\title{
TRASVASE DISCURSIVO DE LOS TEXTOS CREATIVOS- LITERARIOS AL PERIODISMO NARRATIVO: LA CRÓNICA
}

\section{DISCURSIVE TRANSFER FROM CREATIVE-LITERARY TEXTS TO NARRATIVE JOURNALISM: THE CHRONICLE}

(iD) María Julia González Conde. Universidad Complutense de Madrid. España

(iD) Gugo Prieto González. Universidad Complutense de Madrid. España

C Teresa Barceló Ugarte. Universidad CEU San Pablo. España

Cómo citar el artículo:

González Conde, M-J., Prieto González, H., y Barceló Ugarte, T. (2022).

Trasvase discursivo de los textos creativos- literarios al periodismo narrativo: la crónica. Revista de Ciencias de la Comunicación e Información, 27, 33-51.

http://doi.org/10.35742/rcci.2022.27.e131

\section{RESUMEN}

El objetivo de este artículo es indagar en el género de la crónica como muestra de periodismo narrativo al ser, desde sus orígenes, reflejo e interpretación justificada de una realidad histórica, literaria y social. Para ello, se ha empleado un método cualitativo y volcado bibliográfico sobre distintos puntos de vista y autores, españoles y latinoamericanos. Se hará una primera valoración y sondeo histórico sobre las diversas estrategias narrativas que, de forma explícita o implícita, y dentro de sus argumentaciones persuasivas, narrativas, evolutivas o contextualizadas han acercado a este género hibrido a la apreciación, sensibilidad e imaginación de sus cronistas junto con su investigación documental y/o experimental. La hipótesis de la que parte este estudio consiste en demostrar que la crónica como género informativo - narrativo, y por ende interpretativo, de acuerdo con sus orígenes y procedencia, posee una peculiar forma de narrar los hechos, de adoptar y adaptarse al lenguaje periodístico, a sus rutinas y condiciones informativas, sin olvidar añadir importantes matices literarios en sus textos. Una particularidad que sin duda supondrá deducir, como resultados y conclusiones de análisis, no sólo un trasvase discursivo de los textos creativos- literarios al periodismo narrativo, en general, y a la crónica, en particular, sino una capitulación a la duda hamletiana sobre la veracidad periodística en la reflexión y representación de la realidad, ¿objetividad u objetivación? Esa es la incertidumbre.

PALABRAS CLAVE: Crónicas, Periodismo, Género narrativo, Literatura, Objetividad. 
María Julia González Conde, Hugo Prieto González y Teresa Barceló Ugarte

\section{ABSTRACT}

The purpose of this article is to investigate the genre of the chronicle as a sample of narrative journalism since its origins as a reflection and justified interpretation of a historical, literary and social reality. For this objetive, using a qualitative method and bibliographic survey on different points of view and authors, Spanish and Latin American, a first assessment and historical survey will be made on the various narrative strategies that, explicitly or implicitly, and within their persuasive, narrative, evolutionary or contextualized arguments, have brought this hybrid genre closer to the appreciation, sensitivity and imagination of its chroniclers together with their documentary and/or experimental research. The hypothesis of this study is to demonstrate that the chronicle as an informative-narrative genre, and therefore interpretative, according to its origins and origin, has a peculiar way of narrating the facts, of adopting and adapting to the journalistic language, to its routines and informative conditions, without forgetting to add important literary nuances in its texts. A peculiarity that will undoubtedly lead to deduce, as results and conclusions of analysis, not only a discursive transfer of creative-literary texts to narrative journalism, in general, and to the chronicle, in particular, but also a capitulation to the Hamlettian doubt about the journalistic veracity in the reflection and representation of reality, objectivity or objectification? That is the uncertainty.

KEYWORDS: Chronicle, Journalism, Narrative genre, Literature, Objectivity.

\section{INTRODUCCIÓN}

Esta investigación surge del objetivo de analizar un tipo de periodismo calificado como narrativo (Angulo Egea, 2014; Herrscher, 2012; Cuartero, 2017b; Sierra y López, 2016) por oponerse a aquél que marca la dinámica de los medios de comunicación, sometido al ritmo de la inmediatez, al tamaño de sus textos o a la sobriedad de sus informaciones.

Hablar de "periodismo narrativo" es designar en buena parte la casi totalidad de la práctica profesional actual, de acuerdo con sus posibilidades descriptivas, expositivas, argumentativas o conversacionales. Incluso cuando a esa modalidad periodística específica se la califique como "no ficcional" estamos olvidando su mediación lingüística, retórica y narrativa que, como cualquier otro género del discurso, exige retomar el hecho acaecido y reproducirlo de nuevo para convertir sus relatos en aceptables y de algún modo creíbles para su audiencia. Lo que viene a configurar, en todo caso, una "mimesis verosímil de lo real” (Chillón, 2017).

Se considera la crónica como un cruce entre periodismo y literatura al contar con un carácter documental a la vez que una libertad formal en su lenguaje (Camenforte, 2019; Carrión, 2012; Chillón, 2014). Una clara oposición al discurso periodístico encorsetado al emplear estrategias literarias que incluso la pudieran alejar "de cualquier propósito de objetividad", cuando el mensaje cronístico es el que se adapta al estilo del autor y no a la inversa Brunetti et.al., 2015, 73-74). 
Aquí se utiliza el término periodismo narrativo en lugar de literario por considerarlo menos confuso y contar con una mayor aceptación por parte de la comunidad científica, sobre todo latinoamericana.

En Latinoamérica, los años 90 y 2000 la crónica se afianza como un género híbrido entre el periodismo y la literatura, a partir de su capacidad para relatar un hecho verídico con una visible participación del yo narrativo, y abarcar un amplio abanico de temas. En este contexto surgen una variedad de medios alternativos y revistas especializadas donde se expresa el mejor periodismo narrativo de nuestro continente (Camenforte, 2019, 12).

Un periodismo narrativo que entiende la crónica como la mirada, la experiencia o el "olfato" de su observador periodista que, sin olvidar las reglas y principal leitmotiv periodístico, incluye recursos creativos, cuasi literarios, a la hora de elaborar su estructura, descripciones, tono, climas, discursos o escenas. Practicar el periodismo narrativo no significa hacer ficción ni inventarse historias, sino crear diseños o contextos atractivos como si de una obra literaria se tratara (Guerriero, 2009).

Los autores Bernal y Chillón (1985, p. 89) ya hablaban en su manual de periodismo de un nuevo estilo, que denominan "periodismo informativo de creación", justificándolo no sólo por una finalidad estética o formalmente cuidada sino por una actitud ética, política e ideológica como desafío al periodismo puramente informativo. Con ello se aludía a la fórmula estadounidense surgida en la década de los sesenta-setenta como protesta al periodismo objetivo y rígido, que, sin embargo, en aquel momento no tuvo gran repercusión en España porque géneros como la crónica, el artículo o la columna de opinión ya entonces contaban con rasgos estilísticos menos estrictos en nuestro país (López Pan, 1996; Chillón, 1999; Cantavella, 2002).

Sin embargo, en la actualidad, la complejidad ecológica de la comunicación y los nuevos procesos de mediación informativa nos colocan en un escenario distinto, más incoherente y a veces incluso contradictorio, por lo que los hábitos de consumo, transmisión de conocimiento y manifestación cultural nos distancian de ese razonamiento cartesiano, garante de una verdad a través de su orden lógico. En este sentido, Chillón (1999, p. 30) sostiene que no hay un estilo periodístico inocente ni transparente, sino variados estilos de comunicación periodística que construyen cada uno su propia realidad representada.

Aquí se hace factible la proposición de intertextualidad productiva teorizada por (Bajtín 1981) y sostenida por (Greenblatt 2001, 62) cuando mantiene que el lenguaje, como la imaginación, al carecer de fronteras, "[...] no puede ser totalmente predicho o controlado". Los textos "dialogan" entre sí como resultado de una universalización dialógica. Y a esa intertextualidad o entrecruzamiento de textos que distintos autores, de manera implícita o explícita, toman a su vez de otros autores, hay que sumarle, entre otros parámetros, la hibridación que un mismo texto puede adquirir según diferentes géneros o modalidades discursivas.

De este modo, cuando Genette habla de "transtextualidad" engloba las categorías generales- o transcendentes- al mismo texto, como los tipos de discurso, sus modos de enunciación, o los géneros literarios a los que pudiera pertenecer. Señala que el 
María Julia González Conde, Hugo Prieto González y Teresa Barceló Ugarte

género es sólo un aspecto del architexto, ya que "[...] el texto en sí mismo no está obligado a conocer, y mucho menos a declarar, su cualidad genérica" (1989, p. 13).

Para este autor, el estilo es la clave de la capacidad poética o literaria de toda clase de textos. Así, cualquiera de ellos, históricos o biográficos, así como ficticios, pueden sobrevivir a su valor original (documental, histórico, filosófico, etc.) gracias al gusto individual o colectivo que revaloriza sus cualidades estéticas, debido a condiciones históricas, sociales, culturales; y por tanto es la subjetividad lo que permite dicha apreciación (Genette, 1991, 10).

\section{ESTADO DE LA CUESTIÓN}

El presente artículo trata de indagar en las principales características que le han propiciado a la crónica a que se convierta en el género periodístico paradigma del periodismo narrativo, por su carácter híbrido entre la cualidad periodística y la literaria, tal como han señalado varios autores en distintas ocasiones (Chillón, 2014; Gil González, 2004; Hartsock, 2000; Kramer, 1995; López Pan, 1996; Rodríguez y Angulo, 2010; Sims, 1995; Vanoost, en 2013, entre otros).

Si nos centramos en su significado etimológico- del latín chronicas y del griego cronosla crónica es entendida como una narración literal de unos hechos, según un orden cronológico; una significación que varía y enriquece su discurso en sus diversas etapas. Si en un primer momento se entendió como relato de acontecimientos desde "dentro a poca distancia física, mental e ideológica" (Gomis, 2008, 117-118), pasó a ser "reveladora de hechos históricos en un orden temporal", para envolverse en la magia de la tradición literaria (Vilamor, 2000, p. 290), hasta convertirse en el género periodístico que ahora conocemos. La crónica admite, pues, una producción diversa y polimorfa que viene acompañada por su visión panorámica a lo largo de su historia. Hipótesis de la que se parte y se expone como argumento de reflexión en este artículo.

Además, en el ámbito periodístico actual el vocablo crónica tampoco encuentra una definición universal y clara en su concepto y significado, ya que encierra ciertos matices diferentes, incluso en disertaciones sobre su identificación como género informativo, que también difieren según la zona geográfica donde se trate, España o Latinoamérica (Jaramillo, 2011; Lago, 2014; Palau y Cuartero, 2018; Puerta, 2017; Rueda, 2012); e incluso su significado puede variar sustancialmente de un país a otro (Parratt, 2008). De este modo, bajo el paraguas periodístico común de género híbrido y polisémico se puede entender: como modalidad breve ligada a la actualidad y como género ambiguo en concepto y forma, como la narración de una noticia con elementos valorativos, que siempre deben ser secundarios (García Núñez, 1985; Lázaro Carreter, 1976; Martínez Albertos, 1988); como "noticia interpretada, valorada, comentada y enjuiciada" (Vilamor, 2000, 341); como género en el límite entre los informativos y los de opinión (Gutiérrez, 1984) o garante de una fórmula ensayística que toma el elemento informativo apenas como punto de partida, (Bernal, 1997; Mateo, 2001); admitirse como producción periodística de "largo aliento" al no seguir la actualidad más inmediata y tratarse de creaciones más extensas y elaboradas (Palau, 2018); formar parte del llamado "periodismo lento" de acuerdo a una información rigurosa, creativa y de calidad (Rosique y Barranquero, 2015); estar a caballo entre la literatura y el periodismo (Brunetti, Luque y Orellana; 2015), en las que 
incluso ambos textos "se abrazan" (López Pan, 1996, p. 123) y, en definitiva, como "un sitio discursivo de fronteras abiertas y porosas" (Bernabé, 2010, p. 6).

Igualmente, el término cronista que, en un primer momento, adquirió matices de narrador de hechos contemporáneos pasó a convertirse en relator de sucesos, recopilador de fuentes o escritor costumbrista, hasta mantenerse en un oficio periodístico con pautas cada vez más claras y precisas, o caracterizarse por su estilo libre y firma de su autor (Borrat, 1989, 122).

A pesar de que la crónica junto con el reportaje- además del artículo y la columna de opinión- son los géneros más proclives a la fórmula del periodismo narrativo o literario, existe una controversia entre los dos primeros, que, en ocasiones, confluyen e invitan a la confusión. García Márquez (2001, p. 2; citado por Yanes, 2006, p. 4) no encuentra bien definidas las fronteras entre la crónica y el reportaje, incluso entre la crónica y el cuento o la novela. "Una crónica es un cuento que es verdad", quedaría como frase emblemática de este escritor.

Para autores como Acosta Montoro (1973) es el reportaje, y no la crónica, el género que comparte más rasgos con la literatura, en contraste con otras estimaciones, como la de Gil González (2004), que señala que el reportaje no puede ser considerado el enlace entre la literatura y el periodismo por ser una invención genuinamente periodística. Yanes (2006, p. 4) precisa la separación clara entre la crónica y el reportaje con la presencialidad o no en el lugar de los hechos, y otros autores (Elías, 2003) marcan esta diferencia en la temporalidad, prescindible en el reportaje y fundamental en la crónica.

Algo similar también ocurre con la ambigüedad entre crónica y artículo. La Gran Enciclopedia Larousse (1987) define la crónica como "un artículo periodístico en el que se comenta algún tema de actualidad". Del mismo modo, Martínez Sousa desarrolla esta acepción calificando a la crónica como "artículo narrativo, valorativo, interpretativo e informativo, de extensión variable y sobre temas de actualidad [...]" (1992, p. 135-136; citado por Gil González, 2004, p. 32). Unas apreciaciones que compartimos con Gil González como erróneas ya que, aunque ambos son géneros interpretativos, la crónica tiene como referente la interpretación de un hecho real, mientras que el artículo sólo expone su opinión o comentario sobre el mismo. En la crónica periodística se combina la narración y la interpretación, como la forma subjetiva en la que se cuentan los hechos.

Lo cierto es que la noticia y la realidad son el hilo conductor de la crónica, tomando elementos de la literatura para la construcción de una historia; sus límites estilísticos convergen en no sobrepasar a la ficción (Puerta, 2011, 56).

Así, la crónica actual, con sus distintos matices y acepciones, se convierte en un género periodístico interesante al conjugar, como señala (Salazar 2005, 3), "lo eterno desde lo perdurable", aceptando una variedad de géneros salvo el ficcional. Para este autor, la hibridación o transdiscursividad de la crónica funciona como un modo de infringir o violentar las reglas, lo establecido. Su inherente voluntad transgresora es el origen de su ambivalencia. 
María Julia González Conde, Hugo Prieto González y Teresa Barceló Ugarte

En una entrevista al cronista Alberto Salcedo Ramos (2017), éste indica que es un grave error asegurar que lo que es literatura no es periodismo o lo que es periodismo no es literatura. Para este periodista colombiano, la crónica es literatura cuando está bien escrita, porque se apoya en la belleza estética, y es periodismo cuando informa, porque permite enterarse de algo que no se sabía. Reflexión que ya había sido realizada por Martín Vivaldi (1998, p. 249) cuando señala que ambas disciplinas se solapan, porque mientras que la literatura tiene mucho de comunicación, el periodismo es subjetivismo sobre la propia realidad.

Albert Chilón $(1999,70)$ considera que no hay pensamiento sin lenguaje, sino pensamiento en el lenguaje. De este modo, Chillón explica que un giro lingüístico en la comunicación periodística, es decir, la toma de conciencia de que conocemos el mundo a medida que lo designamos con palabras y lo construimos sintácticamente en enunciados, conlleva la superación de la hipótesis de que existe una realidad objetiva externa a los sujetos.

Un género, el de la crónica, que adquiere un sinfín de significaciones presentes pero que también en el pasado alcanzó matices diferentes, como se refleja brevemente en este artículo, a través de una exposición de distintos autores e investigadores, para llegar a unos resultados, que se relacionen con la práctica del periodismo actual en España.

\section{METODOLOGÍA}

El método de análisis empleado se basa en una investigación explicativa a través de una exploración teórica sustentada en la revisión bibliográfica, detectando los principales discursos, interpretaciones, análisis y reflexiones sobre el tema central de este artículo, la crónica en su contexto histórico. Para ello, se ha realizado un volcado de la bibliografía básica sobre la línea de investigación y utilizado de forma sistemática dos bases de datos relevantes sobre artículos científicos: Google Académico y Dialnet. Con filtrado de aquellos textos y monográficos sobre periodismo narrativo y literario o sobre el propio género de crónica que, centrados en aspectos localistas o excesivamente genéricos o técnicos, no respondan al objeto de búsqueda.

Se considera este artículo como una primera etapa de estudio, donde se selecciona la crónica como punto de partida y muestra de análisis por varios motivos. En primer lugar, por ser la crónica, junto con el reportaje, el adalid del periodismo narrativo fundamentalmente en Latinoamérica, pero también en España; por sus antecedentes literarios e históricos, lo que quizá supone la mayor dificultad para su clasificación como género periodístico puro; y, por último, y como razón principal, por contar con evidentes rasgos subjetivos en su narración, que la distancian de los demás géneros informativos propiamente dichos.

Se trata de una primera valoración sobre este eje central, la crónica y su evolución e influencia histórica, que será completada con otra posterior a este trabajo inicial en donde se elegirán herramientas metodológicas a través del análisis de contenido de las crónicas actuales desde sus distintas variantes para contestar al objetivo planteado sobre la crónica actual en España y su incorporación, o no, en el periodismo narrativo, 
así como buscar los parámetros comparativos que la contemplen dentro de una calidad periodística y objetividad informativa mínima.

En el recorrido histórico propuesto en este artículo se procura reconstruir y precisar las valoraciones y los rasgos más destacados de la crónica en tres de sus momentos más significativos: cuando se encuentra vinculada al fenómeno historiográfico, al mundo literario y al periodístico. Con el objetivo de buscar y reflexionar sobre los antecedentes que otorgan a la crónica actual ese carácter híbrido que, aun manteniendo un carácter narrativo, interpretativo y, por ende, subjetivo, ha alcanzado en la práctica periodística un reconocimiento informativo u objetivo de la realidad.

\section{MARCO TEÓRICO}

Claudia Darrigrandi (2013, p. 125) plantea una clasificación sobre la evolución histórica de la crónica latinoamericana que divide en tres etapas clave: la primera se inicia con Las crónicas de Indias, cuyos relatos eran compilaciones históricas referidas a la colonización española; la segunda simboliza la crónica modernista, a finales del siglo XIX, y la tercera, representa la actual producción cronística, identificada dentro del periodismo narrativo. En este artículo, se ajustará la crónica a tres campos de estudio: el historiográfico, el literario y el periodístico.

\subsection{La crónica como narración histórica}

La crónica, entre sus diversas técnicas y modalidades, es considerada como forma originaria de la historiografía y uno de los procedimientos más utilizados para transmitir la historia de generación a generación. Una de las acepciones que hace la RAE sobre la crónica es la de "narración histórica en que se sigue el orden consecutivo de los acontecimientos". Asimismo, el Diccionario crítico etimológico castellano e histórico, de Corominas (1981) también admite su carácter histórico en la "Primera Crónica General”.

No obstante, entre los siglos IX y XIV, y en casi todo el occidente cristiano, la crónica es "[...] manejada como relato propagandístico puesto al servicio de una causa" (Gil, 2004 , p. 27). Una aserción que ya había sido presentada por Manuel Bernal cuando advierte que:

[...] las relaciones y crónicas no se limitan al relato objetivo de los hechos de actualidad, sino que la pura información convive con la interpretación hasta, en ocasiones, con la propaganda, especialmente cuando el relato gira entorno a personas regias o grandes señores (1997, p. 10-11).

De este modo, como también afirman Alvar, Mainer y Navarro (1997, p. 107-205), la proliferación de crónicas y obras historiográficas de todo tipo, que se dan desde principios del siglo XII, constituyen la primera muestra de la utilización de una lengua romance peninsular y de un género en la redacción de obras históricas. Y es a partir de Alfonso X (siglo XIII) cuando la historiografía en lengua romance adquiere gran importancia al servir de formación de la nobleza, que encuentra en las crónicas ejemplos del pasado, justificaciones del presente y, en ocasiones, entretenimientos dignos. 
María Julia González Conde, Hugo Prieto González y Teresa Barceló Ugarte

En la literatura medieval, de tradición oral, señala Gil (2004, p. 28-29), la crónica como relato histórico que amplió su campo semántico introduciendo narraciones heroicas y de aventuras, con retratos y diálogos entre personajes que se alejan de sus fuentes originales y se acercan más a la creatividad y ficción literaria que al rigor histórico. Sirva de ejemplo la Crónica del condestable Miguel Lucas de Iranzo o la Crónica del famoso cavallero Cid Ruy Díaz Campeador. Este mismo autor destaca dos de los aspectos historiográficos fundamentales que constituirán su signo de identidad posterior. Por un lado, su versión como relato de acontecimientos según un orden cronológico; en segundo lugar, la importancia que alcanza el autor del texto como "testigo privilegiado de los hechos" que, con independencia de los fines ideológicos que defienda, es el encargado de estructurar los sucesos según dictamina su creatividad, siempre y cuando obedezca a una serie de características impuestas por la historiografía (Gil, 2004, p. 28).

En esta misma línea, Juan Carlos Gil, citando a Bernal Rodríguez (1997, p. 39) y a Baquero Goyanes (1998, p. 55), ve una cierta similitud y un hilo conductor entre este tipo de crónica medieval y la novela histórica; en la que también se destaca el cuidado del lenguaje y recurso retórico por parte de su relator que, siendo muchas veces testigo de esos hechos, gracias a su minuciosidad descriptiva, cumple la doble función de entretener y seducir con sus narraciones y de servir como vehículo de comunicación periodística. Siguiendo esas mismas premisas y remontándonos mucho más en el tiempo, se pueden encontrar en alguno de los escritos griegos, como leyes, contratos, decretos o acuerdos, documentos "[...] con ciertas características de la crónica" (Vilamor, 2000, p. 282), como también en las epopeyas, cantares de gesta o romances. En este caso, cuando las crónicas se incluyen en los romances, sus características también guardan cierta semejanza con las actuales (García y Cuartero, 2016, p. 4).

La literatura que interesa al mundo griego del siglo $V$ a.C. se manifiesta a través de cientos de escritores que trabajan en el género de la Historia. Y aquí destacaron Los nueve libros de Historia, de Heródoto de Halicarnaso y la Historia de la Guerra del Peloponeso de Tucídides. Nos referiremos a esta última obra del general ateniense que sirvió en esta guerra y que escribió una crónica de este conflicto desde la realidad de los acontecimientos vividos, y que además fue contextualizada en un mundo sin intervenciones divinas, con el objetivo de difundirlo al mundo griego. A diferencia de Herodoto que habló sobre las Guerras Médicas medio siglo después de que se concluyeran. Una revolucionaria metodología empleada por Tucídides en sus relatos cronísticos- tratamiento de las fuentes, exacta cronología y pretensión de objetividad de los hechos narrados- que le proporcionó el calificativo actual del mejor historiador de la antigüedad clásica y consideración como el primer historiador científico. Otra innovación especial para tener en cuenta de este predecesor cronístico es la forma entretenida y comprensible de escribir y estilo austero de sus discursos, evitando figuras retóricas propias de sus predecesores y elementos épicos y anecdóticos que pudieran romper el hilo conductor de su narrativa.

Sin embargo, tampoco se puede obviar en esta trayectoria histórica y diversa de hacer crónica, la producción de una recreación literaria de un hecho histórico. Para esta perspectiva se acude a la epopeya griega y al primer texto literario occidental que 
relata un hecho histórico: la guerra de Troya/llión. La llíada, el poema épico más antiguo de la literatura occidental escrito por Homero cinco siglos después del hecho acaecido (siglo VIII a.C.) que, junto con la Odisea, fueron considerados por los griegos de la época clásica y por las generaciones posteriores como relatos históricos reales; aunque no era historia sino epopeya, en ella se traslucía los valores e ideales griegos de la época (Sanz, 2010).

\subsection{La crónica en el ámbito social y literario}

En España la práctica de este tipo de crónica literaria y social aparece a partir del siglo XIX, con la figura de Mariano José de Larra y Ramón de Mesonero Romanos como sus máximos representantes, y continúa en el $\mathrm{XX}$ con escritores modernistas que también combinan la literatura con el periodismo.

El costumbrismo decimonónico español simbolizado por escenas locales, lugares, conductas o instituciones viene representado en artículos de costumbres, de carácter didáctico, moralizador, humorístico o satírico. Su objetivo, como precursor del realismo y naturalismo, es reflejar la realidad de manera objetiva, sin opiniones ni interpretaciones. El mismo José de Larra así lo expresa en su artículo La vida de Madrid:

Soy periodista; paso la mayor parte del tiempo, como todo escritor público, en escribir lo que no pienso y en hacer creer a los demás lo que no creo. ¡Cómo se puede escribir alabando! Esto es, que mi vida está reducida a querer decir lo que otros no quieren oír (Larra, 1968, p. 259-260).

Sin embargo, sus textos- como señala Curvardic- tienen carácter metatextual al utilizar como tema su propio proceso de escritura:

La incorporación de este procedimiento nos permite comprobar que incluso las estéticas orientadas a la observación objetiva de la realidad social, como ocurre con la periodística, terminan por anular o dejar en suspenso el efecto de realidad que en principio guía sus propuestas (Curvardic, 2010, p. 95).

Del mismo modo, la crónica modernista, como la costumbrista, en su coherencia entre literatura y periodismo marca una nueva tipología en la que el escritor debe adaptarse a las reglas de mercado periodístico, al gusto del receptor, a la pluralidad de los temas tratados, a prestar atención al espacio de la página donde escribe y a unos plazos de entrega, lo que se traduce en "[...] una seria limitación al desarrollo artístico de un escritor" (Palau-Sampio, 2018, p. 198; citando a Mateo, 2001, p. 31). De este modo, "[...] la crónica sólo podía aparecer como una suerte de avanzada esteticista dentro del periódico que exhibía otro modo de escritura al mismo tiempo que marcaba el límite del discurso informativo" (Bernabé, 2010, p. 1).

Para Brunetti, Luque y Orellana (2015, p. 64) la crónica de finales del siglo XIX y principios del $X X$ determinaría el origen de la crónica de autor o simplemente de "la crónica" por antonomasia, porque a estos reconocidos escritores modernistas (costumbristas) se unen, en las redacciones de los periódicos, otros cronistas 
María Julia González Conde, Hugo Prieto González y Teresa Barceló Ugarte

anónimos que emprendieron un nuevo proceso innovador del periodismo decimonónico en busca de un nuevo público lector.

\subsection{La crónica en el ámbito periodístico}

En España son numerosos los autores, tanto escritores como periodistas que, desde mediados del siglo pasado, y sobre todo a partir de la década de los noventa, ejercen el periodismo narrativo, como cronistas, articulistas o columnistas. Hablamos de periodistas-escritores de la talla de Rosa Montero, Juan Luís Cebrián, Carmen Rigalt, Raúl del Pozo, Francisco Umbral o Arturo Pérez Reverte, por poner sólo una lista incompleta de excelentes autores españoles.

[...] En las primeras décadas del siglo XX parece trazarse una línea clara entre periodistas y literatos, pero también entre la noticia y la crónica como en el espacio de la colaboración periodística en la que la narrativización es siempre admirable Brunetti et.al., 2015, p. 68).

Una tradición de obras periodísticas que, sin abandonar el rigor y la veracidad de la información, hacen uso de las herramientas propias de la literatura, y que han continuado a lo largo del siglo XX, dentro y fuera de nuestras fronteras. Autores latinoamericanos como Rodolfo Walsh, Gabriel García Márquez o Elena Poniatowska; nombres reconocidos, como Ernest Hemingway, Truman Capote, Tom Wolfe o Norman Mailer, en Estados Unidos; o George Orwell, Ryszard Kapuściński, Oriana Fallaci y Svetlana Aleksiévich, en Europa (Palau y Cuartero, 2018, p. 963).

En España, también aparece una nueva identidad periodística, la de los cronistas profesionales presentes en el lugar de los hechos, a modo de reporteros, que deben no sólo transmitir información sino buscarla e interesar a los lectores a través de su olfato e intuición periodística, su forma de escribir y estilo personal. Encontramos periodistas-escritores de la talla de Manuel Vázquez Montalbán, Maruja Torres o Manuel Leguineche. De este modo, la crónica entra a formar parte de los géneros informativos aunque, como señala Martín Vivaldi, como un híbrido que supera la propia información y el reporterismo al añadir el elemento interpretativo y valorativo de la realidad. Para este autor, el periodismo no es un arte literario menor, sino un arte literario diferente (1998, p. 249).

\subsection{Rasgos del Periodismo narrativo o literario actual}

En estos momentos, existe una ligera controversia en el ámbito académico sobre cómo nominar el espacio de convergencia entre periodismo y literatura (Angulo Egea, 2014; Carrión, 2012; Chillón, 2014; Herrscher, 2012). Como apunta Bak (2011, p. 130), la concepción de periodismo narrativo o literario es una construcción social y cultural, influenciada por la cultura periodística en la que se desarrolla, por lo que es susceptible de presentarse bajo diversas denominaciones (Josephi et al., 2009, pp. 75-76).

A los apelativos clásicos de periodismo literario, nuevo periodismo o literatura periodística, se han ido sumando en los últimos años etiquetas como 'Literary news writing' (Parratt 2003, pp. 96-100), 'Nuevo nuevo periodismo' (Boynton, 2015) o 'Slow 
journalism' (Greenberg, 2012, p. 381; Rosique y Barranquero, 2015, p. 453), que amplían las referencias apuntadas por Chillón (2014). En el contexto anglosajón ha primado durante décadas la apuesta por el término 'Literary journalism' (Sims, 1984; Roiland, 2015), aunque en las últimas décadas se ha impuesto con fuerza la de 'Periodismo narrativo' (Ángulo, 2017; Cuartero, 2017a, p. 54; Palau, 2018; Palau y Cuartero, 2018, pp. 963-964).

De este modo, mientras que algunos autores consideran que ambos mundos son dispares, por sus métodos y objetivos, otros afirman que determinados géneros- como la crónica- reflejan elementos de creación cercanos a la literatura. Esta relación entre literatura y periodismo es objeto de numerosos trabajos de investigación.

Hay que señalar, además de las similitudes expuestas, que existen claras divergencias entre la materia periodística y la literaria como la función de inmediatez informativa supuestamente veraz, de fácil asimilación y comprensión para su público consumidor que se contrapone a un público literario más concreto que no busca, entre sus múltiples expectativas, lo más novedoso de la actualidad sino el disfrutar sin prisas del estilo formal y de la belleza expresiva de sus textos. Unas diferencias que se ven mitigadas en el periodismo narrativo cuya función informativa introduce elementos y recursos lingüísticos propios de la literatura.

Elegimos esta definición que parece sintetizar la reciprocidad sobre la literatura y el periodismo narrativo actual:

Entendemos o definimos periodismo narrativo como un fenómeno periodístico que mezcla periodismo y literatura además de historia, ensayo, sociología y documentación y que, sin abandonar su propuesta de informar y contar una historia verídica, lo hace utilizando diversas herramientas de forma que construyen una estructura narrativa tan atractiva como la de cualquier texto de ficción, pero siempre sin renunciar a sus principios veraces (Cuartero, 2017a, p. 44).

\section{ANÁLISIS DE RESULTADOS}

Se comprueba que la denominación del espacio de confluencia entre periodismo y literatura genera polémica en el ámbito académico, aunque no parece que este bautismo resulte menos problemático para sus propios autores, que definen su actividad bajo un heterogéneo abanico de opciones, lo que evidencia que la cuestión terminológica y conceptual dista mucho de estar resuelta. Sin embargo, periodistas españoles entrevistados por Palau y Cuartero (2018, p. 269), entre 2015 y 2016, como Xavier Aldekoa, Alberto Arce, Álex Ayala Ugarte, Nacho Carretero, Ander Izagirre o Virginia Mendoza, identifican su obra bajo la etiqueta de periodismo narrativo. Su justificación se basa en que se trata de creaciones periodísticas que se nutren de las técnicas compositivas y estilísticas de la literatura.

Asimismo, la aparición de nuevos canales de publicación, con revistas de referencia como Gatopardo o Etiqueta Negra, o de editoriales y colecciones volcadas en el periodismo narrativo, ha despertado la atención en torno a un género que permite la 
María Julia González Conde, Hugo Prieto González y Teresa Barceló Ugarte

apuesta periodística por formatos largos, enfoques novedosos y la libertad creativa que requiere el periodismo narrativo (Palau y Cuartero, 2018, p. 262).

Ya no es suficiente informar (Bello y López García, 2004, p. 28). El periodismo quiere aprovechar la herencia recibida de estos siglos y buscar nuevas vías que respondan a los retos actuales. La vuelta a las raíces da fuerza para emprender uno de los principales desafíos: contribuir a la gestión y divulgación del conocimiento.

Uno de los objetivos del periodismo narrativo se encuentra en el componente retórico, en el deseo de convencer, persuadir y conquistar al receptor, para obtener uno de los principales y tradicionales fines de la crónica: la transmisión de conocimiento, dejando huella de la sociedad y de la época en la que se escribe.

El periodismo narrativo, a través de sus crónicas, es una forma de escritura que, por sus características, que incluyen encontrar personajes, recrear acciones y contextos, quiere mantener una memoria viva de las civilizaciones, de la historia que palpita, que seguirá viva y cobrará validez cada vez que alguien se dedique a estudiarla.

El cronista, historiador, escritor o periodista, siempre ha sido apreciado además de como conocedor de la materia como testigo del hecho, sorteador y difusor de sus fuentes directas, estableciendo la proporción equilibrada entre la dosis de información adecuada y el comentario oportuno.

Asimismo, la crónica ha estado asociada a la claridad expositiva con el objetivo de una mejor comprensión. Y salvo en ocasiones muy excepcionales, tanto entre los cronistas de narraciones históricas como en los autores literarios, como en el caso por ejemplo de los modernistas, las crónicas siempre han pretendido adaptarse a un lenguaje más usual y reconocido por el gran público.

Hay que señalar que la crónica, en estos momentos, es el género periodístico por excelencia en Latinoamérica. La Fundación Nuevo Periodismo Iberoamericano le ha dado un impulso a un género que había sido visto como menor, ha consolidado la figura del cronista y del maestro de cronistas que, a su vez, ha desencadenado en una serie de talleres que han ayudado a su consolidación y difusión en todo el continente (Puerta, 2016, p. 494).

\section{PUNTOS CONCLUYENTES}

La literatura y el periodismo mantienen y han mantenido una relación estrecha que los han emparentado y enriquecido en sus distintas etapas históricas. A pesar de que ambas disciplinas trabajan con la palabra y el lenguaje, siempre han intentado diferenciarse una de la otra. Así, desde la concepción clásica se ha dicho que la literatura está directamente relacionada con la ficción, y que la intención del escritor debe ser liberar a sus lectores del mundo real para llevarlos a un universo ficticio, donde se puedan apreciar sensaciones y experiencias imposibles de percibir en aquél.

Dentro de estas relaciones cabe destacar el periodismo narrativo, y su manifestación en la crónica, que asume el compromiso con la información y el componente estético, además de la particularidad de trascender en el tiempo. La crónica es una de las 
tipologías textuales que, aunque no es ficcional, puede considerarse como formas de literatura, porque la ficción no debe determinarse como único criterio para definir la literariedad, su carácter literario.

En el periodismo narrativo, el lenguaje de la crónica trasciende lo meramente informativo, representa la realidad, no es la realidad. Pretende que esa representación, esa creación, que no implica falsedad, sea viva, se actualice en la mente del receptor para convertirlo en testigo.

Entre las múltiples muestras y definiciones de una crónica, se estima que puede ser considerada a rasgos generales, y desde sus orígenes heredados, como un género híbrido -histórico, literario o periodístico- entre la información del hecho que se narra y la interpretación, opinión o valoración de este. Un género genuinamente latino diferente a cualquier género del periodismo anglosajón (story y comments).

Vargas Llosa (2013) se refiere al trabajo de la periodista argentina Leila Guerriero con la idea de que el periodismo puede ser una de las bellas artes y producir obras de valía, sin renunciar a su obligación primordial, que es informar:

[...] técnicas que son las de los mejores novelistas, pero su método de estructurar los textos, utilizando distintos puntos de vista y jugando con el tiempo, así como dando al lenguaje una importancia primordial — tanto en la elección de las palabras como en sus silencios-, no llegan jamás a prevalecer sobre la voluntad informativa, están siempre al servicio de ésta, sin permitir que la forma deje de ser funcional y termine por trascender aquella subordinación a la realidad objetiva, que es el dominio exclusivo y excluyente del periodismo.

En este sentido, se encuentra una gran imprecisión conceptual cuando en los medios audiovisuales actuales españoles se da paso "a la crónica de un corresponsal..." si lo que realmente se anuncia es una noticia en la que no existe ninguna valoración por parte de su autor.

En definitiva, la crónica es un género que siempre ha estado vinculado al cuidado formal y manejo del lenguaje por lo que está y ha estado relacionado con estructuras narrativas propias de la literatura, aunque limitado por la objetividad documental y el referente real, temporal e incluso presencial. Sin embargo, son precisamente los elementos subjetivos enjuiciadores, aunque no sean verificables, junto con el estilo narrativo, los que dan eficacia y relevancia a su mensaje.

Las crónicas, desde cualquier perspectiva analizada, son difíciles de clasificar al encontrar tantas variedades como los estilos de quienes las escriben. Cada cronista imprime su sello personal y en esa reconstrucción de la realidad, cada crónica se erige en testimonio directo de una época y representa la parte de un todo. Está muy ligada a los cambios sociales y tecnológicos de los diferentes periodos históricos.

Una mezcolanza de géneros, de colores literarios, de matices informativos e interpretativos que supone la convergencia de todas estas categorías en una a la que se refiere Haro Tecglen (1998, p. 12; citado por Gil, 2004, p. 36) "[...] hoy está todo despiezado: lo que a veces era una línea continua de narración ha estallado y se 
encuentran trozos aquí y allá. Metido lo personal entre lo general; la vida propia entre los datos de la historia. Esto es una crónica".

\section{REFERENCIAS}

Acosta Montoro, J. (1973). Periodismo y Literatura. Madrid: Ediciones Guadarrama.

Alvar, C., Mainer, J. C. y Navarro, R. (1997). Breve historia de la literatura española. Madrid: Alianza.

Angulo Egea, M. (2017). Inmersiones. Crónica de viajes y periodismo encubierto. Barcelona, Universitat de Barcelona.

Angulo Egea, M. (2014). Introducción. En: M. Angulo (coord.) Crónica y mirada: aproximaciones al periodismo narrativo. Madrid: Libros del K.O.

Bajtín, M. (1981). The dialogic imagination. Austin: University of Texas Press.

Bak, J. S. (2011). Introduction. En: Bak, John. S. y Reynolds, B. Literary Journalism across the globe. Journalistic traditions and transnational influences. Estados Unidos: Universidad de Massachusetts Press.

Baquero Goyanes, M. (1998). ¿Qué es la novela? ¿Qué es el cuento? Murcia: Universidad de Murcia.

Bello Janeiro, D. y López García, X. (coord.) (2004). La divulgación del conocimiento en la sociedad de la información. Santiago de Compostela: Escola Galega de Administración Pública.

Bernabé, M. (2010). Sobre márgenes, crónica y mercancía. Boletín del Centro de Estudios de Teoría y Crítica, 15, 65-80.

Bernal Rodríguez, M. (1997). La crónica periodística: tres aproximaciones a su estudio. Sevilla: Padilla Libros.

Bernal Rodríguez, M. y Chillón, LI. A. (1985). Periodismo informativo de creación, en El periodismo como género literario, Barcelona: Mitre.

Boynton, R. S. (2015). El nuevo nuevo periodismo. Conversaciones sobre el oficio con los mejores escritores estadounidenses de no ficción. Barcelona: Edicions Universitat de Barcelona.

Borrat, Héctor (1989). El periódico, actor político. Barcelona: Editorial Gustavo Gili.

Brunetti, P.; Luque, D. y Orellana, M. (2015). Volviendo sobre la crónica y las añejas tensiones entre periodismo y literatura. Question. Revista especializada en Periodismo y Comunicación, 1(48), 62-77. 
Camenforte, M. (2019). El periodismo narrativo en la crónica policial argentina. Licenciatura en Comunicación social; Mendoza: Universidad Nacional de Cuyo.

Cantavella, J. (2002). La novela sin ficción: cuando el periodismo y la narrativa se dan la mano. Oviedo: Septem Ediciones.

Carrión, J. (2012). Mejor que ficción. Crónicas ejemplares. Barcelona: Anagrama.

Corominas-Pascual, J. (1981). Breve Diccionario etimológico castellano e histórico. Madrid: Gredos.

Cuartero Naranjo, A. (2017a). El concepto de nuevo periodismo y su encaje en las prácticas periodísticas narrativas en España. Doxa Comunicación, 25, 43-62

Cuartero Naranjo, A. (2017b). Periodismo narrativo (2008-2016): Una nueva generación de autores españoles. (Tesis doctoral inédita). Universidad de Málaga. España.

Curvardic García, D. (2010). Las relaciones de los escritores costumbristas y modernistas con las empresas periodísticas. Reflexiones, 89(2), 85-97.

Chillón, A. (2017). El concepto de "facción": índole, alcance e incidencia en los estudios periodísticos, Cuadernos Info, 40, 91-105. https://doi.org/10.7764/cdi.40.1121

Chillón, A. (2014). La Palabra Facticia. Literatura, periodismo y comunicación. Barcelona: Universitat Autònoma de Barcelona.

Chillón, A. (1999). Literatura y Periodismo: una tradición de relaciones promiscuas. Barcelona: Universidad Autónoma de Barcelona.

Darrigrandi, C. (2013). Crónica latinoamericana: algunos apuntes para su estudio, Cuadernos de literatura, 17(34), 122-143.

Elías, C. (2003). Los suplementos especializados como guetos de noticias en la prensa generalista. El caso de los científicos y sanitarios. Ámbitos: revista internacional de comunicación, 9(10), 171-186.

García Galindo, J. A. y Cuartero Naranjo, A. (2016). La crónica en el periodismo narrativo, Revista Famecos, 23(4). https://doi.org/10.15448/1980$\underline{3729.2016 . s .24926}$

García Márquez, G. (2001). Sofismas de distracción. Sala de prensa. Web para profesionales de la comunicación iberoamericanos, 29(2).

García Núñez, F. (1985). Cómo escribir para la prensa. Madrid: Ibérico Europea.

Genette, G. (1991). Ficción y Dicción. Barcelona: Lumen. 
Genette, G. (1989). Palimpsesto. Madrid: Taurus.

Gil González, J. C. (2004). La crónica periodística. Evolución, desarrollo y nueva perspectiva: viaje desde la historia al periodismo interpretativo. Global Media Journal, 1(1), 26-39.

Gomis, L. (2008). Teoría de los géneros periodísticos. Barcelona: Editorial UOC.

Greenberg, S. (2012). Slow Journalism in the Digital Fast Lane. En Keeble, R. L. y Tulloch, J. Global Literary Journalism: Exploring the Journalistic Imagination. Nueva York: Peter Lang.

Greenblatt, S. (2001). Racial memory and literary history. PMLA, 116(1), 48-63.

Guerriero, L. (2009). ¿Dónde estaba yo cuando escribí esto? En Guerriero, L. Frutos extraños, crónicas reunidas 2001-2008. Madrid: Alfaguara.

Gutiérrez Palacio, J. (1984). Periodismo de opinión. Madrid: Paraninfo.

Haro Tecglen, E. (1998). Hijo del siglo. Crónica. Madrid: El País Aguilar.

Hartsock, J. C. (2000). A history of American literary journalism: The emergence of a modern narrative form. Massachusetts: University of Massachusetts Press.

Herrscher, R. (2012). Periodismo narrativo. Cómo contar la realidad con las armas de la literatura y qué enseñan las vidas y las obras de los grandes maestros de la no ficción. Barcelona: Edicions Universitat de Barcelona.

Jaramillo Aguelo, D. (2011). Collage sobre la crónica latinoamericana del siglo veintiuno. En Jaramillo Aguelo, D. (ed.) Antología de la crónica latinoamericana actual. Madrid: Alfaguara.

Josephi, B., Cowan, E. y Müller, C. (2009). Differently drawn boundaries of the permissible in German and Australian literary journalism. Literary Journalism Studies, 1(1), 67-78.

Kramer, M. (1995). Literary journalism. A new collection of the best American nonfiction. New York: Ballantine Books.

Lago, M. C. (2014). Crónica latinoamericana: evolución de un género proteico para narrar lo cotidiano. Revista de investigación del departamento de humanidades y ciencias sociales, 2, 3-16.

Larra, M. J. de (1968). La vida de Madrid; en Artículos completos. Madrid: Editorial Aguilar.

Lázaro Carreter, F. (1976). ¿Qué es la literatura? Universidad Internacional Menéndez Pelayo. 
López Pan, F. (1996). La columna periodística. Teoría y práctica. Pamplona: EUNSA.

Martín Vivaldi, G. (1998). Géneros periodísticos. Reportaje, crónica, artículo; Madrid: Paraninfo.

Martínez Albertos (1988). Curso general de redacción periodística. Madrid: Mitre.

Mateo, A. (2001). Crónica y fin de siglo en Hispanoamérica (del siglo XIX al XXI). Revista Chilena de Literatura, 59, 13-39.

Palau-Sampio, D. (2018). Las identidades de la crónica: hibridez, polisemia y ecos históricos en un género entre la literatura y el periodismo. Palabra Clave, 21(1), 191-218. https://doi.org/10.5294/pacla.2018.21.1.9

Palau-Sampio, D. y Cuartero-Naranjo, A. (2018). El periodismo narrativo español y latinoamericano: influencias, temáticas, publicaciones y puntos de vista de una generación de autores. Revista Latina de Comunicación Social, 73, 961979. 10.4185/RLCS-2018-1291

Parratt, S. F. (2008). Géneros periodísticos en prensa. Quito: Ciespal.

Parratt, S. F. (2003). Introducción al reportaje: antecedentes actualidad y perspectivas. Santiago de Compostela: Universidad de Santiago de Compostela.

Puerta Molina, A. A. (2017). Crónica latinoamericana ¿Existe un Boom de la no ficción?". Estudios sobre el Mensaje Periodístico, 23(1), 165-178. https://doi.org/10.5209/ESMP.55589

Puerta Molina, A. A. (2016). La crónica latinoamericana actual: lo maravilloso real. Análisis del periodismo narrativo de Alberto Salcedo Ramos. (Tesis doctoral) Universidad Autónoma de Madrid.

Puerta Molina, A. A. (2011). El periodismo narrativo o una manera de dejar huella de una sociedad en una época, Anagramas, 9(18), 47-60. https://doi.org/10.22395/angr.v9n18a3

Rodríguez Rodríguez, J. M. y Angulo Egea, M. (2010). Literatos y periodistas: el origen de un matrimonio de conveniencia. En Rodríguez Rodríguez, J. M. y Angulo Egea, M. (coord.), Periodismo literario: naturaleza, antecedentes, paradigmas y perspectivas. Madrid: Editorial Fragua.

Roiland, J. (2015). By any other name: The case for Literary Journalism. Literary Journalism Studies, 7(2).

Rosique-Cedillo, G. y Barranquero-Carretero, A. (2015). Periodismo lento (Slow journalism) en la era de la inmediatez. Experiencias en Iberoamérica. El profesional de la información, 24(49), 451-462. 
María Julia González Conde, Hugo Prieto González y Teresa Barceló Ugarte

Rueda-Acedo, A. R. (2012). Miradas transatlánticas: el periodismo literario de Elena Poniatowska y Rosa Montero. Estados Unidos: Purdue University Press.

Salazar Escalante, J. (2005). La Crónica: Una Estética de la Transgresión, Razón y Palabra, 10(47).

Salcedo Ramos, A. (2017). Reflexiones sobre la crónica. Entrevista en RELATA (Red de Escritura Creativa) (entrevista; 8 de mayo de 2017). Iniciativa del Ministerio de Cultura de Colombia.

Sanz Díaz, B. (2010). Historia del Pensamiento Político Premoderno. Universidad de Valencia.

Sierra Caballero, F. y López Hidalgo, A. (2016). Periodismo narrativo y estética de la recepción. La ruptura del canon y la nueva crónica latinoamericana. Estudios sobre el Mensaje Periodístico, 22(2), 915-934. https://doi.org/10.5209/ESMP.54243

Sims, N. (1995). The art of Literary Journalism. En SIMS, Norman; KRAMER, Mark. Literary journalism. A new collection of the best American nonfiction. New York: Ballantine Books.

Sims, N. (1984). The literary journalists. New York: Ballantine Books.

Tucídides. (1986). Historia de la Guerra del Peloponeso. Editorial Gredos: Madrid.

Vanoost, M. (2013). Journalisme narratif: proposition de définition, entre narratologie et éthique. Les Cahiers du journalisme, 25, 140-161. https://www.cahiersdujournalisme.net/pdf/25/9.Marie-Vanoost.pdf

Vargas Llosa, M. (19 de mayo de 2013). Periodismo y creación: 'Plano americano'. El País. https://elpais.com/elpais/2013/05/16/opinion/1368714188 384998.html

Vilamor, José R. (2000). Redacción periodística para la generación digital: los grandes cambios técnicos, económicos y culturales exigen profundas transformaciones en el campo del Periodismo. Madrid: Universitas.

Yanes Mesa, R. (2006). La crónica, un género del periodismo literario equidistante entre la información y la opinión. Espéculo. Revista de estudios literarios, 32. 


\section{AUTORES}

\section{Julia González Conde}

Proviene del ámbito profesional de la radio y la televisión pública (RTVE) y es Profesora Contratada Doctor de la UCM, desde 2012, con un sexenio de investigación. Docente en el Área de Audiovisual, del departamento de Periodismo y Nuevos Medios, en la Facultad de Ciencias de la Información, de dicha Universidad, donde ha impartido Periodismo Multimedia, Información en Radio e Información en Televisión, en el Grado de Periodismo. Además de otras materias audiovisuales en el Máster Universitario de Periodismo Multimedia Profesional, Máster profesional de Radio (RNE) y seminarios especializados en técnicas de expresión oral para profesionales de la radio y la televisión en el Instituto de RTVE.

Orcid ID: https://orcid.org/0000-0001-8375-8420

Google Scholar: https://scholar.google.es/citations?user=w4NTnQQAAAAJ\&hl

\section{Hugo Prieto González}

Es licenciado en Derecho y Filosofía y Letras. Profesor de Secundaria y Bachillerato en el área de Lengua y Literatura en la Comunidad de Madrid. Coordinador durante el curso 2020-21 del Plan Refuerza en dicha Comunidad. Asimismo, está vinculado al departamento de Periodismo y Nuevos Medios de la Facultad de Ciencias de la Información de la Universidad Complutense de Madrid, donde está realizando su tesis doctoral.

Orcid ID: https://orcid.org/0000-0003-2463-3817

Google Scholar: https://scholar.google.es/citations?user=06-3ofoAAAAJ\&h|

\section{Teresa Barceló Ugarte}

Profesora Adjunta del departamento de Comunicación Audiovisual y Publicidad de la Facultad de Humanidades y Ciencias de la Comunicación de la Universidad CEU San Pablo desde el curso académico 2005/2006. Coordinadora del Grado en Comunicación Digital desde su puesta en marcha en 2012 hasta 2018. Imparte docencia en los grados de Comunicación Audiovisual, Comunicación Digital, Periodismo y Publicidad y RRPP, así como en el Máster Universitario en Periodismo Cultural y en el Máster Universitario en Relaciones Públicas y Organización de Eventos.

Orcid ID: https://orcid.org/0000-0003-1722-5065

Google Scholar: https://scholar.google.es/citations?user=19ZCU2IAAAAJ\&hl=es 